\title{
Optimal sampling time-point for cyclosporin A concentration monitoring in heart transplant recipients
}

\author{
YIXIN JIA, XU MENG, YAN LI, CHUNLEI XU, WEN ZENG, YUQING JIAO and WEI HAN \\ Department of Cardiac Surgery, Capital Medical University Affiliated Anzhen Hospital, Beijing 100029, P.R. China
}

Received January 4, 2018; Accepted July 13, 2018

DOI: $10.3892 / \mathrm{etm} .2018 .6711$

\begin{abstract}
The present study was performed to determine an optimal time-point for monitoring the concentration of the immunosuppressive drug cyclosporin A (CsA) in heart transplant patients and its efficacy in the prevention of transplant rejection. A total of 32 transplant recipients were randomly assigned for three treatment approaches. Recipients in groups $A(n=11), B(n=13)$ and $C(n=8)$ received oral administration of CsA at doses of 3.2, 3.5 and $4.4 \mathrm{mg} / \mathrm{kg}$, respectively. The plasma CsA concentrations were examined at $2 \mathrm{~h}$ intervals over $12 \mathrm{~h}$. Furthermore, their correlation with the $4 \mathrm{~h}$ pharmacokinetic profiles as the area under the plasma CsA concentration vs. time curve $\left(\mathrm{AUC}_{0-4 \mathrm{~h}}\right)$ were calculated The efficacy of CsA in inhibiting cardiac allograft rejection was assessed at $2 \mathrm{~h}$ after oral CsA intake (C2) and adverse events of the drug were examined in the $\mathrm{C} 2$-monitored recipients. The plasma CsA concentration rapidly increased in most recipients with a peak level detected at $\sim 2 \mathrm{~h}$ after dosing. Regression analysis revealed that among all time-points assessed, the $\mathrm{CsA}$ had the highest correlation with the $\mathrm{AUC}_{0-4 \mathrm{~h}}$ at $\mathrm{C} 2$. At $\mathrm{C} 2$, increasing $\mathrm{CsA}$ doses exhibited a positive association with the measure of $\mathrm{AUC}_{0-4 \mathrm{~h}}$. The efficacy of increasing CsA target levels at $\mathrm{C} 2$ in preventing heart transplant rejection was comparable, as the survival rate was $100 \%$ in all of the treatment groups. However, the proportion of recipients with side effects in group A was obviously lower than that in the other two groups. In conclusion, $\mathrm{C} 2$ is an ideal time-point for monitoring plasma $\mathrm{CsA}$ levels with a utility for individualising the next scheduled dose for each patient to ensure that target levels are maintained and achieve a high efficacy and safety
\end{abstract}

Correspondence to: Dr Xu Meng, Department of Cardiac Surgery, Capital Medical University Affiliated Anzhen Hospital, 2 Anzhen Road, Beijing 100029, P.R. China

E-mail: xumeng_med@126.com

Abbreviations: CsA, cyclosporin A; $\mathrm{r}^{2}$, correlation coefficient; HT, heart transplantation; MMF, mycophenolate mofetil; EMB, endomyocardial biopsy

Key words: cyclosporin A, heart transplantation, CsA concentration at $2 \mathrm{~h}, \mathrm{AUC}_{0-4 \mathrm{~h}}$, correlation coefficient of CsA therapy in heart transplant recipients (clinical trial no. 12002610).

\section{Introduction}

Heart transplantation (HT) is a therapeutic option for patients with end-stage heart or coronary artery disease when all other treatments have failed $(1,2)$. The use of immunosuppressive regimens following HT has demonstrated improved graft longevity through reduction of early graft loss due to acute rejection $(3,4)$. However, most immunosuppressive drugs cause a large spectrum of adverse effects and increase the risk of malignancy, which contributes to a leading cause of mortality in HT patients $(5,6)$.

Cyclosporin A (CsA) is an immunosuppressant medication commonly used for the prophylaxis of graft rejection with improvement in long-term survival $(7,8)$. Therapeutic drug monitoring of CsA in transplant patients has markedly evolved in routine clinical practices incethis drug requires dosage individualization $(9,10)$. Although monitoring of the CsA concentration at $2 \mathrm{~h}$ after administration (C2) is recommended for the evaluation of drug exposure in transplant recipients $(11,12)$, the optimal time-point for monitoring CsA target levels remains controversial in HT patients (13).

The aim of the present study was to explore the optimal time-point for CsA concentration monitoring in the long-term treatment of HT patients. The results confirm that the $\mathrm{C} 2$ approach serves as a clinical tool to monitor CsA target levels and the occurrence of adverse events in HT recipients.

\section{Materials and methods}

Patients and inclusion criteria. A total of 32 patients who received HT surgery between June 2012 and February 2014 at the Capital Medical University Affiliated Anzhen Hospital (Beijing, China) were recruited for the present study. These patients included 25 males and 7 females aged between 22-53 years (median age, 37.5 years). The patients' characteristics and the etiologies of heart failure were evaluated. The left ventricular size and function, evaluated as the left ventricular end diastolic diameter (LEVDD) and ejection fraction (EF), are presented in Table I. The major inclusion criteria for the recipients were as follows: i) No hypertension or hyperlipidemia diagnosed with in 6 months prior to the HT operation, and no medical history there of; ii) blood glucose levels within the normal range over 6 months prior to the operation; 
iii) normal results in liver and kidney function tests and iv) no contraindications for steroids, mycophenolate mofetil (MMF) and CsA. The transplant hearts were obtained from organ donors who were Chinese citizens with brain death as defined by The Red Cross Society of China.

Therapeutic procedures. The subjects were assigned to three groups according to their plasma CsA levels at C2 after an initial dose of CsA ( $4 \mathrm{mg} / \mathrm{kg} / \mathrm{day}$ ) was given post-operatively. After one week of treatment, the recipients in groups A, B and $\mathrm{C}$ received oral CsA (Neoral, Novartis, Switzerland) at the doses of $3.2,3.5$ and $4.4 \mathrm{mg} / \mathrm{kg}$ once a day, respectively, for 6 consecutive months. In the following 6 months, CsA treatment was maintained at the doses of $2.8 \mathrm{mg} / \mathrm{kg}$ in group $\mathrm{A}$, $3.1 \mathrm{mg} / \mathrm{kg}$ in group B and $3.9 \mathrm{mg} / \mathrm{kg}$ in group C, respectively. The target plasma concentrations of CsA $(\mathrm{ng} / \mathrm{ml})$ at $\mathrm{C} 2$ in the patient groups are presented in Table II. All patients were simultaneously administered oral prednisone (Douglas Pharmaceuticals Ltd., Auckland, New Zealand) at $60 \mathrm{mg} /$ day for 15 days and gradually reduced to $20 \mathrm{mg}$ /day until the end of the study. MMF was purchased from Hoffmann-LaRoche (Basel, Switzerland) and administered to patients at $500 \mathrm{mg}$ twice a day during the entire study.

Preparation of samples and analysis of CsA concentration. Blood samples obtained from patients were prepared following the manufacturer's protocol and CsA concentrations in samples were evaluated using a fluorescence polarization immunoassay (Abbott Pharmaceutical Co., Ltd.,Lake Bluff, IL, USA). In brief, $2.0 \mathrm{ml}$ venous blood was collected at different time-points at 2-h intervals over $12 \mathrm{~h}$ after oral administration of CsA. Following lysis and precipitation of blood cells, the supernatants were collected after the heparin anti-coagulated blood samples were centrifuged $\left(9,000 \mathrm{x}\right.$ g for $5.0 \mathrm{~min}$ at $\left.4^{\circ} \mathrm{C}\right)$. For pharmacokinetic analysis, quantification of the immunosuppressant CsA in plasma was performed by a TDxFLx-SYSTEManalyzer (Abbott Laboratories, Irving, TX, USA).

Sample collection was performedby collecting serial blood samples over a limited period (0-12 h) after administering a single dose of CsA. The area under the plasma CsA concentration versus time curve (AUC) was calculated to estimate the extent of drug absorption after dosing (14). In the presentstudy, the CsA levels at specific time-points were compared with the 4-h pharmacokinetic profiles $\left(\mathrm{AUC}_{0-4}\right)$ from the recipients, since the latterapproach to monitor CsA exposure has been used in immunosuppressive regimens $(13,15)$.

Myocardial biopsy. Endomyocardial biopsy (EMB) has been proven to be a diagnostic tool for the surveillance of cardiac allograft rejection and identification of myocardial diseases (16). EMB was performed in a supine position with local anesthesia, and the biopsy was performed through a catheter threaded into the patient's heart through the jugular vein under ultrasound guidance. The clinicians used moving images to guide the catheter to the targeted area. Once in position, a special device with jaws on the tip was used to remove small pieces of tissue from the heart muscle $(16,17)$.

The histological grades of organ rejection in EMB specimens were classified according to the International Society for Heart and Lung Transplantation (ISHLT) (17).
Clinical observation of the efficacy and safety of the immunosuppressive therapy. The efficacy of CsA in the management of HT recipients who were receiving combination therapy with two drugs (MMF, $500 \mathrm{mg}$ twice a day and prednisone, $20 \mathrm{mg} /$ day) at the same dosages and time was examined according to the survival rate of HT patients and the proportion of patients with adverse events. Since the survival rates vary with the length of time post-HT, the rates were expressed as a percentage of the population proportion to the survivors only, at one year after HT.

Adverse events associated with the use of CsA for the prophylaxis of cardiac allograft rejection were examined. They mainly included hypertension, diabetes mellitus, hyperlipidemia and renal in sufficiency diagnosed by a high serum creatinine level (>133 $\mu \mathrm{mol} / \mathrm{l})$. The incidence of side effects was expressed as the percentage of affected subjects in each group.

Statistical analysis. Values are expressed as the mean \pm standard deviation and as a percentage/distribution within the study cohort. Statistical analysis was performed using SPSS version 21.0 (IBM Corp., Armonk, NY, USA). One-way analysis of variance was implemented for comparison of independent variables (Tukey's test). The correlation between the plasma CsA levels at specific sampling time-points and the $\mathrm{AUC}_{0-4}$ was estimated by calculating Pearson's correlation coefficient $\left(r^{2}\right)$. The $\chi^{2}$ test was performed to analyze the significance of population distribution among the grouped recipients. $\mathrm{P}<0.05$ was considered to indicate a statistic all significant difference.

\section{Results}

Pharmacokinetic profile of CsA absorption. The effect of drugs is frequently associated with their concentration in the blood; hence it is useful to establish a concentration-time association after a single administration of CsA. Changes in the plasma CsA concentration in HT recipients $(n=32)$ were observed at $2 \mathrm{~h}$ intervals over a period of $12 \mathrm{~h}$ and $\mathrm{CsA}$ levels were obtained just before drug administration. The pharmacokinetic profile of CsA is presented in Fig. 1, displaying the mean plasma CsA concentration in the transplant recipients. Most patients exhibited similar variation of CsA plasma levels during the 12-h period following administration. Of note, sampling between 0 and $4 \mathrm{~h}$ appeared to provide a reliable indication of total CsA exposure. In general, the plasma CsA concentration-time curve of the recipients exhibited an increasing trend initially and reached a peak level at $2 \mathrm{~h}$ following administration, after which the levels dropped again to reach a stable, lower level from 6-12 h.

Correlation between CsA and AUC. CsA concentrations were measured by collecting blood samples over the time period of 0-12 h after dosing at 2-h intervals. The $\mathrm{r}^{2}$ value was calculated for the correlation between plasma CsA levels taken at specific time-points and the $\mathrm{AUC}_{0-4 \mathrm{~h}}$ (Fig. 2). According to the regression analysis, the $\mathrm{r}^{2}$ values varied significantly for CsA concentrations detected at different blood sampling times (Fig. 2A). The $\mathrm{r}^{2}$ values were 0.29 at $\mathrm{C} 0,0.38$ at $\mathrm{C} 1,0.84$ at $\mathrm{C} 2,0.57$ at $\mathrm{C} 4,0.66$ at $\mathrm{C} 6,0.59$ at $\mathrm{C} 8,0.41$ at $\mathrm{C} 10$ and 0.31 at $\mathrm{C} 12$. Of note, the highest $\mathrm{r}^{2}$ value was obtained at $\mathrm{C} 2$, thereby indicating the applicability of this time-point for monitoring the CsA absorption in the transplant recipients. 
Table I. Characteristics of patients and evaluation of left ventricular size and function.

\begin{tabular}{lrllrrr}
\hline Group & No. & Males & Age (years) & Dilated (schemic) cardiomyopathy & LEVDD (mm) & EF (\%) \\
\hline A & 11 & $7(36.6)$ & $42.7 \pm 12.1$ & $9(2)$ & $73.5 \pm 15.7$ & $19.6 \pm 5.7$ \\
B & 13 & $8(61.5)$ & $45.6 \pm 9.7$ & $12(1)$ & $71.3 \pm 8.3$ & $22.3 \pm 8.7$ \\
C & 8 & $6(75.0)$ & $41.3 \pm 16.7$ & $7(1)$ & $74.5 \pm 6.9$ & $20.5 \pm 9.6$ \\
\hline
\end{tabular}

Values are expressed in $\mathrm{n}(\%)$ or the mean \pm standard deviation. Statistical analysis indicated no significant differences in the parameters between any two groups $(\mathrm{P}>0.05)$. EF, ejection fraction; LEVDD, left ventricular end diastolic diameter.

Table II. Plasma cyclosporine A concentration (ng/ml) at C2 in heart transplant recipients.

\begin{tabular}{lcc}
\hline Group & 1st six months & 2nd six months \\
\hline A & $600-800$ & $400-600$ \\
B & $>800-1,000$ & $>600-800$ \\
C & $>1,000-1,200$ & $>800-1,000$ \\
\hline
\end{tabular}

The correlation of the plasma CsA concentration examined by measurement of the $\mathrm{AUC}_{0-4 \mathrm{~h}}(\mathrm{ng} / \mathrm{h} / \mathrm{ml})$ with that determined at $\mathrm{C} 2$ is displayed in (Fig. 2B). The levels of CsA at C2 were significantly enhanced with increasing doses of the immunosuppressive agent and ranged from 600 to $1,200 \mathrm{ng} / \mathrm{ml}$ in these $\mathrm{HT}$ recipients $(\mathrm{n}=32)$. In parallel, the $\mathrm{AUC}_{0-4 \mathrm{~h}}$ values $(\mathrm{ng} / \mathrm{h} / \mathrm{ml})$ displayed a dose-dependent increment in the CsA-treated recipients. A positive correlation between the CsA levels at $\mathrm{C} 2$ and the $\mathrm{AUC}_{0-4 \mathrm{~h}}$ was determined in the study cohort with an $\mathrm{r}^{2}$ value of $0.84(\mathrm{P}<0.05)$. It was therefore indicated that the $\mathrm{C} 2$ monitoring strategy is suitable for assessing the target levels of CsA in HT recipients at one time-point.

Clinical significance of CsA therapy. Survival rates and adverse events for recipients with HT rejection were assessed in line with the strategy of CsA monitoring at $\mathrm{C} 2$ and the results are presented in Fig. 3. The efficacy of CsA as an immunosuppressive therapy was observed to be excellent with a survival rate of $100 \%$ for all patients within the first year after HT (Fig. 3A). On further analysis by cardiac pathologic examination, no acute cellular rejection was detected in the transplanted cohort during the first six months according to standardized cardiac biopsy grading. In the following six months, immune responses for certain recipients with ISHLT grades I-II were notably weakened and gradually recovered to normal conditions in the CsA-treated recipients after increasing the MMF dosage to $1.0 \mathrm{~g}$ twice a day. The recipients who received CsA therapy had a survival rate of $100 \%$ in the present clinical trial.

The most common adverse events in the CsA-treated patients were observed by using the $\mathrm{C} 2$ monitoring approach. Clinical manifestations of the side effects mainly included hypertension, diabetes mellitus, hyperlipidemia and renal insufficiency in the recipients (Fig. 3B). The frequencies of adverse events are expressed as a percentage of affected patients in each recipient group. The occurrence of hypertension, hyperlipidemia and renal insufficiency was relatively common in the study cohort, affecting 18.2, 18.2 and 18.2\%, in group $\mathrm{A}(\mathrm{n}=11), 23.1,30.8$ and $23.1 \%$ in group $B(n=13)$ and $37.4,50.0$ and $62.5 \%$ in group $\mathrm{C}(\mathrm{n}=8)$, respectively. Incidence of diabetes mellitus was had a rate of $9.1 \%$ in group A, $7.7 \%$ in group B and $12.5 \%$ in group C. Statistically significant differences in the occurrence of hypertension, hyperlipidemia and renal insufficiency between group $\mathrm{C}$ and either group A or B were identified $(\mathrm{P}<0.01)$. In addition, there was a statistically significant difference in incidence of hyperlipidemia between groups $\mathrm{A}$ and $\mathrm{B}(\mathrm{P}<0.01)$.

Blood creatinine is a fairly reliable indicator of renal health. The dependency between the CsA levels at C2 and the creatinine content at the same time-point was therefore assessed in the cohort of HT recipients. The creatinine concentration ( $\mu \mathrm{mol} / \mathrm{l})$ in the blood at $\mathrm{C} 2$ was significantly enhanced with the CsA dose increasing from 400 to $1,200 \mathrm{ng} / \mathrm{ml}$ (Fig. 3C). Furthermore, linear regression between the two variables was clearly exhibited in the cohort $\left(\mathrm{r}^{2}=0.79\right.$ and $\left.\mathrm{P}<0.05\right)$.

\section{Discussion}

The pharmacokinetic profile of CsA was first determined in HT recipients after a single administration of the immunosuppressant based on the fact that CsA has a relatively narrow therapeutic window (18). The results of the present study indicated that oral CsA was rapidly taken up into the recipients' blood with a peak level detected at $\sim 2 \mathrm{~h}$ after administration. The pharmacokinetic analysis of CsA indicated that the plasma CsA concentration rapidly increased in the transplant recipients, followed by a sharp drop in CsA levels. The present results were consistent with those of previous studies reporting that the time window for CsA therapeutic drug monitoring is narrow $(19,20)$. Given that plasma the CsA concentration varied cross the serial sampling time-points with a peak value of the CsA level observed at $2 \mathrm{~h}$ after administration, it is indicated that $\mathrm{C} 2$ is an optimal sampling time-point, and is superior to the other time-points for monitoring the efficacy of CsA in inhibiting HT rejection.

To explore if a blood sample taken at $2 \mathrm{~h}$ after oral administration of $\mathrm{CsA}$ is a better estimate of the $\mathrm{AUC}_{0-4 \mathrm{~h}}$ than other time-points in HT recipients, the $\mathrm{r}^{2}$ value for the correlation of the $\mathrm{AUC}_{0-4 \mathrm{~h}}$ with the plasma CsA concentration at each sampling time-point from 0 to $12 \mathrm{~h}$ was determined. The values of the Pearson's Correlation indicated that at $\mathrm{C} 2$, the $r^{2}$ value was markedly higher than those at the other time-points, and this high correlation suggested that the CsA target levels at this single time-point reflected the drug exposure, therefore rendering it suitable for therapeutic 


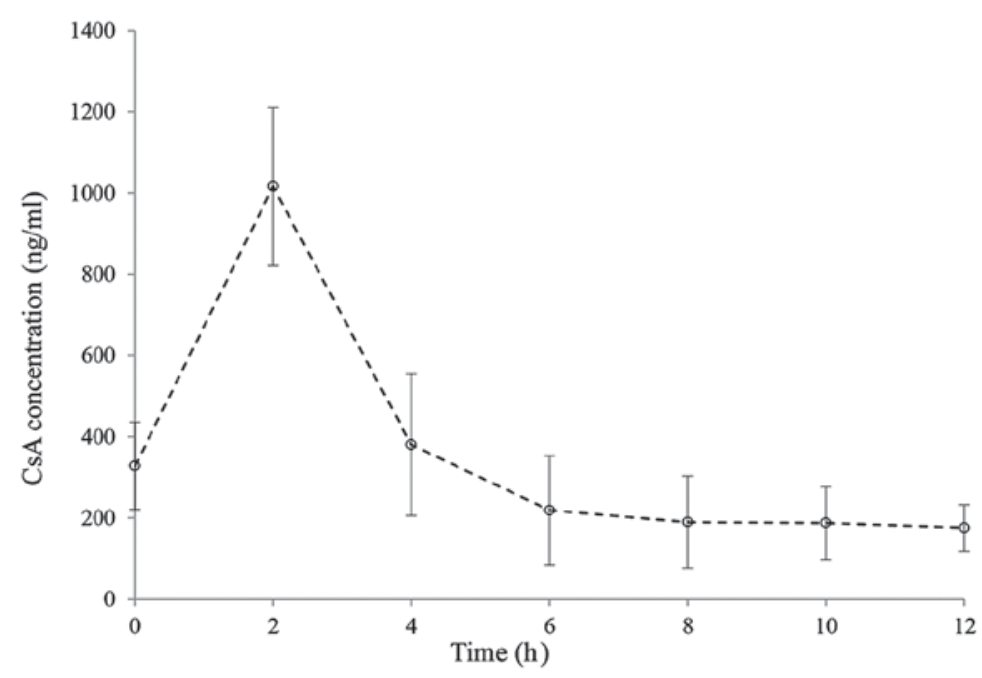

Figure 1. Pharmacokinetic profile of CsA. The pharmacokinetic profiles of individual recipients were observed by measuring the plasma CsA concentration every $2 \mathrm{~h}$ over a time period of $0-12 \mathrm{~h}$. The mean values for CsA levels $(\mathrm{ng} / \mathrm{ml})$ were determined to generate CsA concentration-time curves. Values are expressed as the mean \pm standard deviation $(\mathrm{n}=32)$. CsA, cyclosporin $\mathrm{A}$.
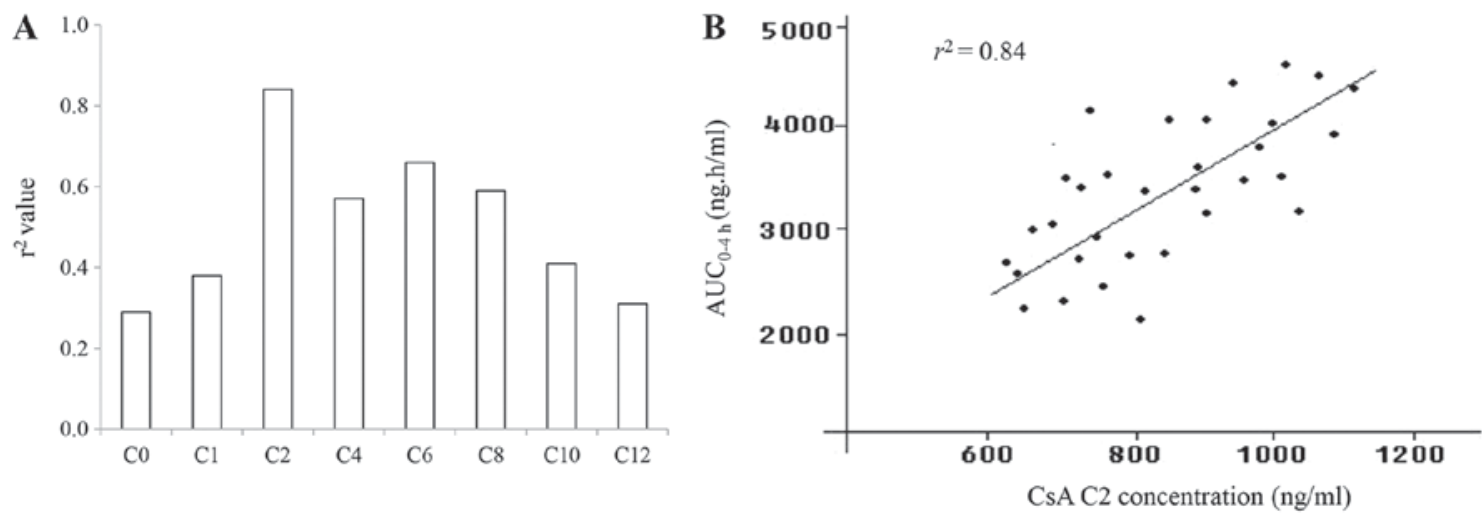

Figure 2. (A) Correlation between the plasma CsA concentration and the $\mathrm{AUC}_{0-4 \mathrm{~h}}(\mathrm{ng} / \mathrm{h} / \mathrm{ml})$ at various time-points after administration (every $2 \mathrm{~h}$ over $12 \mathrm{~h}$ ). (B) Correlation scatter plot for the $\mathrm{AUC}_{0-4 \mathrm{~h}}$ vs. the CsA levels at $\mathrm{C} 2$ in heart transplant recipients $(\mathrm{n}=32)$. A positive correlation between the CsA levels at $\mathrm{C} 2$ and the $\mathrm{AUC}_{0-4 \mathrm{~h}}$ was identified with an $\mathrm{r}^{2}$ value of $0.84(\mathrm{P}<0.05)$. $\mathrm{AUC}_{0-4 \mathrm{~h}}$, area under the curve of the plot of plasma CsA concentration against the time $(0-4 \mathrm{~h})$; CsA, cyclosporin A; C2, 2-h time-point after CsA administration.

monitoring of the immunosuppressant levels. The utility of the $\mathrm{AUC}_{0-12 \mathrm{~h}}$ has been studied in transplant recipients receiving CsA therapy $(21,22)$; however, this monitoring approach is not clinically feasible due to the added time, expense and inconvenience for transplant recipients. The area under the curve over $4 \mathrm{~h}$ after administration has been conceived for monitoring of the plasma CsA concentration in patients receiving immunosuppressive therapy $(15,23)$. The results of the present clinical trial demonstrated that the $\mathrm{C} 2$ levels exhibited a good correlation with the measured $\mathrm{AUC}_{0-4 \mathrm{~h}}$ value, confirming that CsA monitoring at $\mathrm{C} 2$ not only accurately reflected the drug absorption but the implementation of this strategy also reduces cost and assessment time in the long-term management of HT recipients.

While monitoring at $\mathrm{C} 2$ has been applied for $\mathrm{HT}$ recipients in clinical practice $(12,24)$, efficacy of this type of monitoring remains controversial (25-27). To verify the feasibility of the $\mathrm{C} 2$ strategy in therapeutic drug monitoring, a regression analysis was employed to evaluate the correlation between the CsA level at $\mathrm{C} 2$ and the $\mathrm{AUC}_{0-4 \mathrm{~h}}$, which was during the absorption phase of CsA in the recipients. The present results indicated that the CsA levels were elevated in parallel with the $\mathrm{AUC}_{0-4 \mathrm{~h}}$ with increasing doses of CsA administered, and at $\mathrm{C} 2$, the highest correlation was obtained with an $\mathrm{r}^{2}$ value of 0.84 . These results indicated that monitoring at $\mathrm{C} 2$ may provide a suitable means of determining subsequent dosing in clinical trials. Due to the high correlation between the drug level at $\mathrm{C} 2$ and $\mathrm{AUC}_{0-4 \mathrm{~h}}$ in CsA-based immunosuppression, it led us to speculate that $\mathrm{C} 2$ may serve as a useful tool for monitoring drug absorption in HT recipients as well as providing information for individualized drug dosing for each patient.

HT recipients who received CsA were grouped according to their plasma CsA levels. The utility of CsA measurement at $\mathrm{C} 2$ in achieving optimal dosing for the prophylaxis of cardiac allograft rejection was examined in the grouped recipients within one year of oral administration of CsA. The results indicated that in the cohort of recipients, a graft survival rate of $100 \%$ was achieved at the indicated time period (1 year) following HT, suggesting that $\mathrm{C} 2$ may be considered as a suitable time-point to assess the efficacy of the immunosuppressant in a 
A

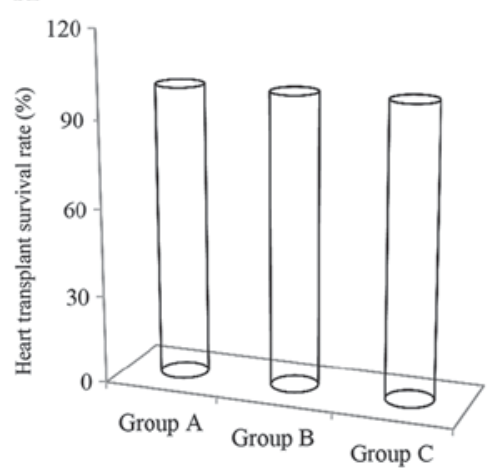

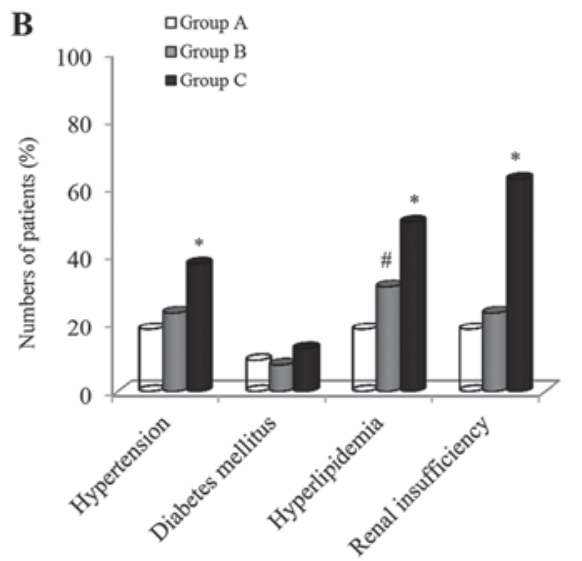

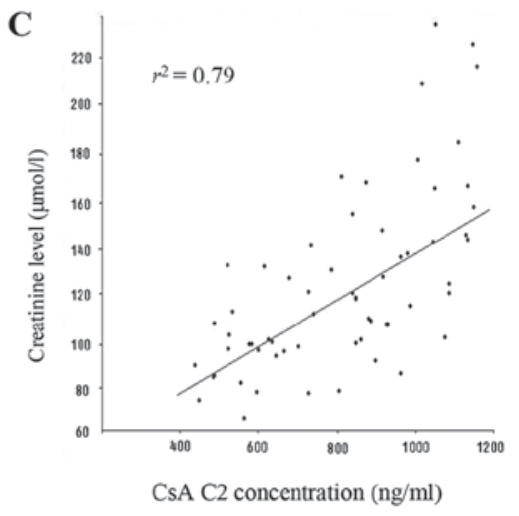

Figure 3. Clinical efficacy and safety of CsA therapy. (A) The survival rate of heart transplant patients treated with CsA for preventing transplant rejection was $100 \%$ in all three groups, according to $\mathrm{C} 2$ monitoring. (B) The proportion of patients with adverse events (\%) was obviously lower in group A compared with that in the other groups. " $\mathrm{P}<0.01$ vs. groups $\mathrm{A}$ and $\mathrm{B} ;{ }^{\#} \mathrm{P}<0.01$ vs. group $\mathrm{A}$. (C) The plasma creatinine levels were enhanced with increasing CsA concentrations at $\mathrm{C} 2$, with a positive correlation between the elevated creatinine content and the level of CsA at C2. CsA, cyclosporin A; C2, 2-h time-point after CsA administration.

broad concentration range for the inhibition of organ rejection. Previous studies have reported that a high survival rate of HT of $>90 \%$ was achieved in the first year after surgery (28-30), which is similar to the present results. However, it is worth noting that this survival rate is only for one year after HT, and that this time is critical to the survival of the recipients. It has been previously reported that a CsA blood concentration of 1,000-1,400 $\mathrm{ng} / \mathrm{ml}$ achieved satisfactory efficacy and safety over six months after HT (31). The present results indicated that intervention with $\mathrm{CsA}$ at low plasma concentrations $(600-800 \mathrm{ng} / \mathrm{ml})$ had a similar therapeutic effect to that achieved with higher doses $(800-1,200 \mathrm{ng} / \mathrm{ml})$ in the patients monitored at $\mathrm{C} 2$, providing evidence that managing the target drug concentration at a relatively low level was necessary in the monitored recipients. Additionally, the lower dosing of the immunosuppressant and less frequent sampling reduced the overall cost during patient treatment.

The incidence of adverse events, which mainly included hypertension, diabetes, hyperlipidemia and renal insufficiency, was examined in the grouped recipients since the immunosuppressant has a narrow therapeutic range and only a small difference between toxic and therapeutic concentrations in clinical practice (19). With increasing CsA levels, the occurrence rate of hypertension, hyperlipidemia and renal impairment was significantly higher in the groups B and C than that in group A, indicating a high incidence of adverse events at higher doses of CsA. Consequently, the monitoring of CsA concentration at $\mathrm{C} 2$ in clinical practice may serve as a sampling strategy for re-adjusting the dosage of the immunosuppressant to reach minimal toxicity in the recipients.

The principal adverse reaction to CsA therapy in transplant recipients is renal dysfunction, so that kidney damage caused by oral CsA requires medical attention $(32,33)$. Treatment with an increasing doses of CsA resulted in elevated creatinine levels, which were correlated with the CsA level at C2 $\left(r^{2}=0.79\right)$. Since the peak level of CsA is associated with nephrotoxicity, it may be concluded that monitoring at $\mathrm{C} 2$ is a reliable approach for adequately observing the occurrence of adverse events, and measurement of CsA at C2 may offer a strategy for reducing the incidence of side effects through providing information for adjusting CsA dosing.

Although previous studies have also reported similar benefits of CsA monitoring at C2 $(9,12,24)$, the present study is of particular importance with regard to the adjustment of the drug treatment regimen for HT recipients, emphasizing that low plasma levels of CsA (400-600 ng/ml) combined with prednisone and MMF achieved a highly satisfactory efficacy and reduced the risk of adverse events during the maintenance treatment of recipients with monitoring at $\mathrm{C} 2$. However, the small number of recruited patients is a limitation of the present study. Consequently, a study with a larger cohort is necessary in the future.

In conclusion, $\mathrm{C} 2$ is the optimal single time-point to measure $\mathrm{CsA}$ in $\mathrm{HC}$ recipients and is representative of the $\mathrm{AUC}_{0-4 \mathrm{~h}}$. C2 monitoring may serve as a reliable technique to optimize the efficacy and safety of CsA therapy by allowing for adjustment of the individualized drug dosage for each recipient in the long-term treatment with the immunosuppressant CsA.

\section{Acknowledgements}

Not applicable.

\section{Funding}

No funding was received.

\section{Availability of data and materials}

All relevant data generated during the study are available from the corresponding author on reasonable request.

\section{Authors' contributions}

YJ designed the experiments and drafted the manuscript. XM, YL, CX, WZ and YJ produced the figures, tables and references. WH provided technical assistance and advice. All authors read and approved the final manuscript and each author believes that the manuscript represents honest work. 


\section{Ethical approval and consent to participate}

The study was approved by the Ethics Committee of Capital Medical University Affiliated Anzhen Hospital (Beijing, China). The Ethics Committee also approved the treatments and tissue collection from patients in accordance with the experimental design and long-term clinical outcome assessment of CsA therapy. The patients and their family members provided written informed consent for inclusion in this study.

\section{Patient consent for publication}

Not applicable.

\section{Competing interests}

The authors declare that they have no competing interests.

\section{References}

1. Burchill LJ: Heart transplantation in adult congenital heart disease. Heart 102: 1871-1877, 2016.

2. Korewicki J: Cardiac transplantation is still the method of choice in the treatment of patients with severe heart failure. Cardiol J 16 : 493-499, 2009.

3. Patel JK, Kittleson M and Kobashigawa JA: Cardiac allograft rejection. Surgeon 9: 160-167, 2011.

4. Patel JK and Kobashigawa JA: Improving survival during heart transplantation: Diagnosis of antibody-mediated rejection and techniques for the prevention of graft injury. Future Cardiol 8 : 623-635, 2012

5. Ippoliti G, Rinaldi M, Pellegrini $C$ and Viganò M: Incidence of cancer after immunosuppressive treatment for heart transplantation. Crit Rev Oncol Hematol 56: 101-113, 2005.

6. Söderlund C and Rådegran G: Immunosuppressive therapies after heart transplantation-the balance between under- and over-immunosuppression. Transplant Rev (Orlando) 29: 181-189, 2015.

7. Banner NR and Yacoub MH: Cyclosporine in thoracic organ transplantation. Transplant Proc 36 (2 Suppl): 302S-308S, 2004.

8. Haverich A and Gorler H: Experience with cyclosporine: From revolution to evolution of immunosuppressive protocols in thoracic organ transplantation. Transplant Proc 36 (2 Suppl): 314S-317S, 2004.

9. Cantarovich M, Barkun J, Giannetti N, Cecere R, Besner JG and Tchervenkov J: History of C2 monitoring in heart and liver transplant patients treated with cyclosporine microemulsion. Transplant Proc 36 (2 Suppl): 442S-447S, 2004.

10. Oellerich M and Armstrong VW: Two-hour cyclosporine concentration determination: An appropriate tool to monitor neoral therapy? Ther Drug Monit 24: 40-46, 2002.

11. Levy GA: C2 monitoring strategy for optimising cyclosporin immunosuppression from the Neoral formulation. BioDrugs 15: 279-290, 2001.

12. Delgado DH, Rao V, Hamel J, Miriuka S, Cusimano RJ and Ross HJ: Monitoring of cyclosporine 2-hour post-dose levels in heart transplantation: Improvement in clinical outcomes. J Heart Lung Transplant 24: 1343-1346, 2005

13. Balram C, Sivathasan C, Cheung YB, Tan SB and Tan YS: A limited sampling strategy for the estimation of 12-hour Neoral systemic drug exposure in heart transplant recipients. J Heart Lung Transplant 21: 1016-1021, 2002.

14. Scheff JD, Almon RR, Dubois DC, Jusko WJ and Androulakis IP: Assessment of pharmacologic area under the curve when baselines are variable. Pharm Res 28: 1081-1089, 2001.

15. Banner NR, David OJ, Leaver N, Davis J, Breen J, Johnston A and Yacoub MH: Pharmacokinetics of oral cyclosporine (Neoral) in heart transplant recipients during the immediate period after surgery. Transpl Int 15: 649-654, 2002.
16. Schulz E, Jabs A, Gori T, Hink U, Sotiriou E, Tschöpe C, Schultheiss HP, Münzel T and Wenzel P: Feasibility and safety of left ventricular endomyocardial biopsy via transradial access: Technique and initial experience. Catheter Cardiovasc Interv 86: $761-765,2015$.

17. Stewart S, Winters GL, Fishbein MC, Tazelaar HD, Kobashigawa J, Abrams J, Andersen CB, Angelini A, Berry GJ, Burke MM, et al: Revision of the 1990 working formulation for the standardization of nomenclature in the diagnosis of heart rejection. J Heart Lung Transplant 24: 1710-1720, 2005.

18. Morris RG: Cyclosporin therapeutic drug monitoring-an established service revisited. Clin Biochem Rev 24: 33-46, 2003.

19. Jorga A, Holt DW and Johnston A: Therapeutic drug monitoring of cyclosporine. Transplant Proc 36 (2 Suppl): 396S-403S, 2004.

20. Midtvedt K: Therapeutic drug monitoring of cyclosporine. Transplant Proc 36 (2 Suppl): 430S-433S, 2004.

21. Frassetto LA, Tan-Tam CC, Barin B, Browne M, Wolfe AR, Stock PG, Roland M and Benet LZ: Best single time point correlations with AUC for cyclosporine and tacrolimus in HIV-infected kidney and liver transplant recipients. Transplantation 97: 702-707, 2014.

22. Mardigyan V, Giannetti N, Cecere R, Besner JG and Cantarovich M: Best single time points to predict the area-under-the-curve in long-term heart transplant patients taking mycophenolate mofetil in combination with cyclosporine or tacrolimus. J Heart Lung Transplant 24: 1614-1618, 2005.

23. Monchaud C and Marquet P: Pharmacokinetic optimization of immunosuppressive therapy in thoracic transplantation: Part I. Clin Pharmacokinet 48: 419-462, 2009.

24. Mathias HC, Ozalp F, Will MB, Borland W, Payne C, Kerr M, Lockhart $\mathrm{J}$ and Murday A: A randomized, controlled trial of $\mathrm{C} 0$ - Vs $\mathrm{C} 2$-guided therapeutic drug monitoring of cyclosporine in stable heart transplant patients. J Heart Lung Transplant 24: 2137-2143, 2005

25. Knight SR and Morris PJ: The clinical benefits of cyclosporine C2-level monitoring: A systematic review. Transplantation 83: 1525-1535, 2007.

26. Narula AS, Murthy M, Patrulu K and Saxena VK: Routine Cyclosporine concentration- $\mathrm{C} 2$ level monitoring. Is it helpful during the early post transplant period? Med J Armed Forces India 60: 326-328, 2004.

27. Zakliczynski M, Krynicka A, Szewczyk M, Wojarski J and Zembala M: Limited utility of cyclosporine C2 monitoring in heart transplant recipients receiving ketoconazole. Transplant Proc 35: 2333-2334, 2003

28. Blanche C, Blanche DA, Kearney B, Sandhu M, Czer LS, Kamlot A, Hickey A and Trento A: Heart transplantation in patients seventy years of age and older: A comparative analysis of outcome. J Thorac Cardiovasc Surg 121: 532-541, 2001.

29. Stehlik J, Edwards LB, Kucheryavaya AY, Benden C, Christie JD, Dipchand AI, Dobbels F, Kirk R, Rahmel AO and Hertz MI; International Society of Heart and Lung Transplantation: The registry of the international society for heart and lung transplantation: 29th official adult heart transplant report-2012. J Heart Lung Transplant 31: 1052-1064, 2012.

30. Colvin-Adams M, Smith JM, Heubner BM, Skeans MA, Edwards LB, Waller C, Snyder JJ, Israni AK and Kasiske BL: OPTN/SRTR 2011 annual data report: Heart. Am J Transplant 13 (Suppl 1): S119-S148, 2013.

31. Wang SS, Chou NK, Chi NH, Huang SC, Wu IH, Wang CH, Yu HY, Chen YS, Tsao CI, Ko WJ and Shun CT: Can cyclosporine blood level be reduced to half after heart transplantation? Transplant Proc 42: 930-933, 2010.

32. Boffini M, Sansone F, Patanè F, Bonato R, Ribezzo M, Iacovino C, Comoglio $\mathrm{C}$ and Rinaldi M: Does everolimus associated with a low dose of cyclosporine in long-term cardiac transplant recipients improve renal function? Initial experience. Transplant Proc 41: 1349-1352, 2009.

33. Damiano S, Ciarcia R, Montagnaro S, Pagnini U, Garofano T, Capasso G, Florio $S$ and Giordano A: Prevention of nephrotoxicity induced by cyclosporine-A: Role of antioxidants. J Cell Biochem 116: 364-369, 2015 .

(i) $($ ) This work is licensed under a Creative Commons Attribution-NonCommercial-NoDerivatives 4.0 International (CC BY-NC-ND 4.0) License. 